\title{
E-ENGINEERING: TEACHING ELECTRICAL ENGINEERING AT DISTANCE
}

\author{
Manuel Gericota $^{1}$, Guillaume Andrieu ${ }^{2}$, Manuel Castro ${ }^{3}$, Paulo Ferreira ${ }^{1}$, \\ \& Andre Fidalgo 1 \\ ${ }^{1}$ Dept. of Electrical Engineering, School of Engineering - Polytechnic of Porto (Portugal) \\ ${ }^{2}$ Faculty of Science and Technology, University of Limoges (France) \\ ${ }^{3}$ Dept. of Electrical, Electronic and Control Engineering, Universidad Nacional de Educación a \\ Distancia (Spain)
}

\begin{abstract}
The e-learning concept was born in the 19th century when the development of the mail services in England enabled the delivering of correspondence courses by mail. Initially restricted to printed material, the content was enriched with audio and video records in the third quarter of the 20th century.

Still, it was the development of the Internet that revolutionized e-learning in the dawn of the 21st century. Apart from facilitating the delivery of a broad set of different materials, the Internet enables a degree of interaction between students and instructor and among students never achieved before, considerably improving the learning process. It also enables the development of remote laboratories, sets of equipment that may be manipulated remotely in real-time to perform experimental work. Initially restricted to the implementation of small experiments, the development of virtual instrumentation enabled the accomplishment of increasingly complex tasks.

In engineering disciplines, laboratory work is widely recognized as essential for students to acquire the required skills. The concept of e-Engineering results from the concatenation of those two previous ideas - e-learning and remote laboratories.

Compared with traditional face-to-face courses, e-Engineering courses require a distinct pedagogical and organizational framework. The experience won with an e-Engineering course developed under a first European project resulted in a new European project currently underway whose aim is to document a set of good practices in e-Engineering. By documenting our experience, our aim is to help other universities to develop and manage their own sustainable e-Engineering courses.
\end{abstract}

Keywords: E-engineering, e-learning, remote laboratories.

\section{Introduction}

The concept of distance learning education emerged in the XIX century when the development of the mail services in England gave to Sir Isaac Pitman, the English inventor of shorthand, the idea of delivering correspondence courses by mail (Matthews, 1999).

The first distance learning undergraduate courses in the world were offered by the University of London through its External System established in 1858 (UoL, 2019). However, the number of courses on offer was very restricted, mainly due to the low degree of interactivity between instructor and student limited to write paper material exchanged via the slow post services. Only a century later, in the third quarter of the 20th century, things started to change with course materials being enriched with audio and video records when the development of the technology enabled students to have access to affordable audio and video players. The United Kingdom's Open University (OU), established in 1969, despite mainly keeping the same way to communicate with students, offered much more diversified materials, ranging from texts and photo materials and audio and video records, to conventional broadcast radio and television programs, complemented by live individual or group sessions over the phone.

However, the major breakthrough was the introduction of the concept of e-learning during the 90s of the XX century, supported by two of the greatest advances in the telecommunications area: the Internet network, and the World Wide Web. The Internet provides a fast, reliable and interactive channel of communication, enabling a degree of interaction comparable to face-to-face classes. The World Wide Web with its hypertext links, enable the delivery of much more diversified and engaging multimedia 
materials, readily available and highly interactive. This revolution was accompanied by the massification of personal computers, which made them affordable and accessible.

Despite all these advances, the undergraduate courses on offer were nevertheless mainly restricted to non-technical areas. The main reason is that engineering courses require students to perform experimental work, be it in chemistry, physics, mechanics, electrical machines, electronics or optics, which entail the access to specific labs and the interaction with equipment and instrumentation.

Until recently the only solution envisaged enabling students in technical areas to perform hands-on labs work has been the use of blended learning solutions, with the entire program conducted online, except for lab classes, which required students to travel to the University campus to perform the indispensable lab work (Zhu, 2010).

With the help of technology, this reality has been changing. Not only virtual tutors will enable speech interaction anytime and with a level of realism close to human interaction (Pells, 2019), but also technical areas are benefiting from the proliferation of remotely accessible laboratories that enable students to perform hands-on lab work remotely, with a level of interactivity and realism never achieved before.

\section{The EOLES course}

Since the beginning of the XXI century that a lot of work has been done in the area of remote laboratories. In the specialized literature there are many examples of different laboratories for different areas of physics and electrical engineering (Albu et al., 2004) (Cardoso \& Gil, 2013) (Garcia-Zubia et al., 2010) (Hercog et al., 2007) (Priem et al., 2011) (Restivo et al., 2009) (Said et al., 2012) (Sousa et al., 2010), each one allowing different degrees of freedom in the configuration of the experiment by the remote user. However, their use has been restricted, operating separately and usually as a complement of on-campus lab classes. Never these labs appeared integrated as part of a fully online undergraduate program in engineering, despite the proven effectiveness of the use of virtual and remote laboratories in the development of essential engineer students' skills, as demonstrated by an extensive study published by Brinson (2015).

The EOLES (Electronics and Optics e-Learning for Embedded Systems) project was a three-year TEMPUS project, financed by the European Commission (EOLES, 2016), whose goal was to bring together all this knowledge with the objective of creating a fully online undergraduate program on Electrical and Computer Engineering. In this first step, only the 3rd year of a Bachelor program was developed, but in the long term, the goal is to remotely offer the complete Bachelor program. The EOLES project comprised 15 Institutions, four European ones from France, Portugal, Belgium and Romania, and 11 from three Maghrebian countries, Algeria, Morocco and Tunisia, part of them with previous experience on the delivering of e-learning courses and/or the development of remote laboratories. The educational goal was the development of higher education in cutting-edge engineering subjects, a national priority defined by the governments of the Maghrebian countries participating in the project struggling with a lack of professionals in this fundamental area for its economic development.

The L3-EOLES (Electronics and Optics e-Learning for Embedded Systems) (L3-EOLES, 2019) was designed as a specialization 3rd-year of a Bachelor's degree and oriented towards a vital telecommunications field, that of the electronics and optics for embedded systems, essential to support the high-speed data transfers required by modern telecommunications networks.

Apart from the theoretical knowledge students must get, they also need to perform experimental lab work, to acquire essential technical experimental skills, whose mastering is indispensable for their future professional success. The execution of laboratory assignments over the Internet required the development of remotely accessible experimental laboratories enabling students to interact in real-time with real experimental setups. Some of the EOLES project partners had extensive experience in the development of remote laboratories used to implement various types of experiments on diverse technological fields, including optics, electronics, and embedded systems (Priem et al., 2011) (Said et al., 2012) (Sousa et al., 2010).

The target population of the course is students already holding 120 European Credit Transfer Units (ECTU) obtained in areas like Physics, Electrical, Electronics, Automation, Optics, Telecommunications, or similar and willing to pursue a career in the specific field of electronics and optics for embedded systems.

The program is divided into fifteen technical units (TUs) that cover a broad list of topics, plus three optional units. These optional units are preparatory TUs provided at the beginning of the 1st semester to level students' knowledge in critical topics for the course - electronics and optics, since students from diverse knowledge backgrounds may apply to be enrolled in this program. 
The course runs for 31 weeks, plus 4 weeks reserved for examinations that take place at each one of semester's end, plus two for make-up exams by year's end.

The aim of the first mandatory TU - Virtual Learning Environment - is to introduce the student to the learning platform and to the interactive tools that support the course dynamics. The remaining 14 TUs are divided into three groups: fundamental sciences - including mathematics and physics; applied sciences - digital and analog electronics, electromagnetic waves, digital signal processing, instrumentation, and optics; and complementary soft skill units, like communication techniques in English and business management, or alternatively, an enterprise internship.

Each TU is organized on a weekly basis and may take three to six weeks. New study materials are released every Mondays. Pre-recorded asynchronous lectures, where a tutor explains the theoretical basis of a given subject, are supported by different types of written and visual resources interspersed with self-evaluation questions - multiple-choice, fill-in-the-blanks, matching exercises -, whose aim is to keep students' interest and attention, breaking long expositive videos. Apart from it, these self-evaluation questions also provide immediate feedback about the students' degree of understanding of the subjects being taught. Students may progress at their own pace, reviewing the material anytime, any number of times, without restrictions. Nevertheless, the student may only continue to the next lecture after the successful completion of the self-evaluation questions associated with the previous one. A range of other materials, including free companion books, web links to other sites containing specialized information and other complementary data, is available to support students' study.

To force students to respect the course schedule compulsory assignments must be delivered each week. These assignments, composed by sets of problems comprising individual or group assessment works, must be uploaded into the platform by the week's end.

Each week, students have the possibility of attending synchronous classes run by the TU tutor where they may clarify any doubts and ask questions related to the content of the TU (figure 1). These classes are based on BigBlueButton, an open source web conferencing tool for online learning (BigBlueButton, 2019). Sessions are recorded and made available to students.

Figure 1. Example of a BigBlueButton -based synchronous online session.

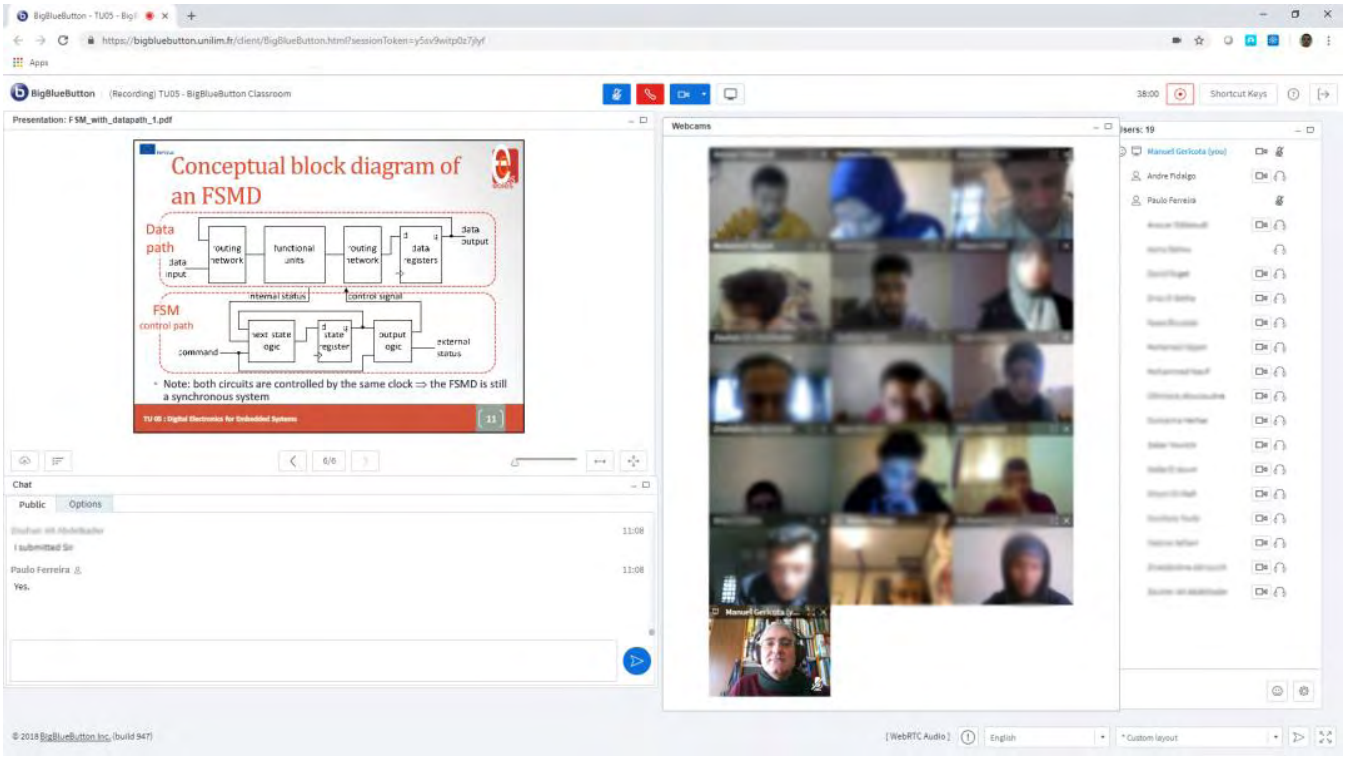

Forums and live chat resources are also available, plus an always open, freely accessible BigBlueButton classroom, a virtual cafe where students may meet anytime they want.

But the main originality of the L3-EOLES course is the remote laboratory used by students to perform online the practical works. Two kinds of laboratory works are included in the remote laboratory:

- Virtual experimentation using professional software running in an application server or open-access software available from different companies and universities;

- Real remote laboratory experiments intended for students to perform real-time monitoring and control of instrumentation and equipment at distance.

The latter is the most innovative part of the remote laboratory. Each hardware instrument (function generator or oscilloscope, for instance) is connected to the Internet and may be monitored and controlled remotely from the students' own computers. 
For each TU a set of laboratory works is prepared by the tutor. Students may access the lab through a dedicated page right from inside TU's page. Through the virtual instrument interfaces that are deployed remotely, which mimic the real instrument's panel available interface, students can change the hardware configuration in real-time. Immediate feedback of their actions is provided through the same or another interface and/or by a high-definition camera, depending on the instrument and nature of the experimental work (figure 2). The camera enables students to see what is happening in the real laboratory and how the real instruments react to their remote commands. This feedback is important for students to be sure the interface they see in their own computers it is not the visible face of a virtual world, but the virtual interface of a real instrument.

Figure 2. Example of an oscilloscope interface deployed remotely and of a laboratory set up with a high-definiton camera.

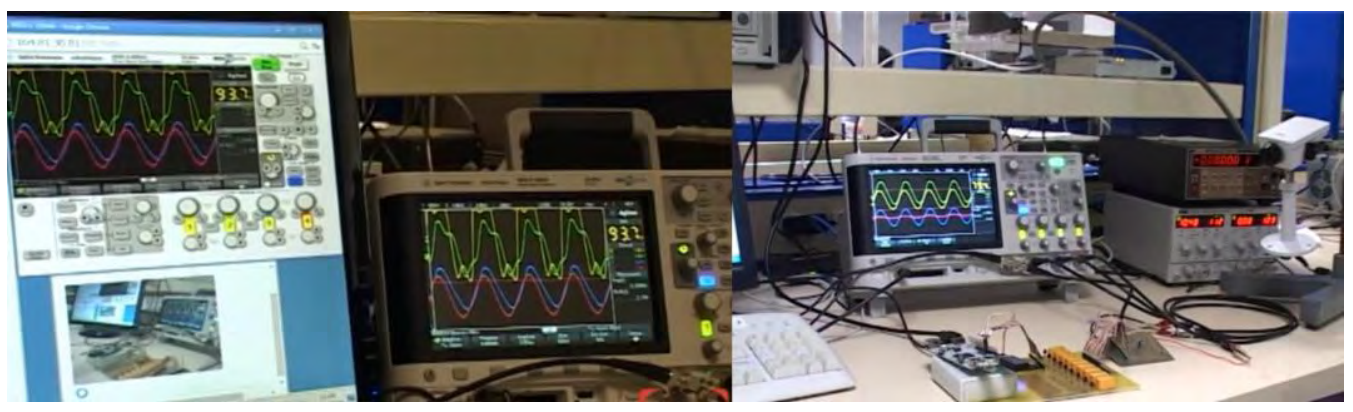

The course accreditation was, from the beginning, one of the main objectives of the project, because only its official recognition would ensure its financial sustainability after the end of the project. The course is currently accredited by the educational authorities of France, Morocco, and Tunisia, which means that all students who successfully complete the course receive not only a Diploma that is recognized inside the European Higher Education Area, but also, in the case of students from Morocco and Tunisia, a diploma issued by one of the accredited universities of their home countries.

The course is also now being offered as a lifelong learning course by some of the EOLES partners' institutions, further ensuring its long-term sustainability.

As far as authors know, the L3-EOLES course is the first where a remote laboratory is used as part of a fully online accredited degree in these areas of engineering to enable students to perform all the required practical work. From the association between e-learning and remote laboratories emerged the concept of e-Engineering.

\section{The e-LIVES project}

The EOLES project ended at the beginning of 2016, but the L3-EOLES course created during the project continues with its 5 th edition underway.

However, despite its success, the adoption of the e-Engineering concept and therefore the development and offer of e-Engineering courses in different engineering fields by higher education institutions is far from happening. Many different aspects related to the development and management of an e-Engineering course need to be addressed by the institutions, aspects that involve a series of other essential elements not strictly related with its pedagogical part, namely: the set up of the necessary infrastructure to support course delivery; the choice of the Learning Management System (LMS) platform; the building of a curriculum; the definition of the learning modules content and schedule; the attainment of the course national accreditation; the training of teachers and technicians; the creation of the contents; the quality assessment; the management of the course; the development of the virtual and remote laboratories.

The aim of the new e LIVES - e-Learning InnoVative Engineering Solutions project (E-LIVES, 2019), a three-year ERASMUS+ European project that started on October 2017, is to create a detailed description of the different parts necessary to set up and run a successful e-Engineering course supported on the consortium partners own successful experience. The documentation produced by the consortium and freely downloadable from the project's website will list and detail each one of the steps necessary to design and develop an e-Engineering course. A first e-Engineering Best Practices Guide, which condenses the partners' research and experience on the creation and delivery of e-Learning and e-Engineering courses, is already available. Other guides covering the different aspects involving the design and development of e-Engineering courses will follow, empowering other institutions to build their own innovative e-Engineering courses in a sustainable way. 


\section{Conclusions}

After the success of the L3-EOLES course, several other institutions showed interest in the results achieved, namely the effective response e-Engineering courses may provide in the formation of a fast-growing number of engineering students. The aim of the new e-LIVES project is to systematize the acquired knowledge, engaging more institutions on the design and development of e-Engineering courses, showing their advantages and benefits to the advancement of higher education on developing countries, as well as the opportunity they represent to create lifelong learning courses able to engage a different public willing to refresh or update their know-how in innovative engineering fields.

The goal of the e-LIVES consortium is to achieve wide dissemination of the Best Practices Guides so institutions may gain enough insights on the advantages e-Engineering courses may bring to them, namely as a viable alternative to crowded classes and as a way to diversify their courses and reach different publics.

\section{Acknowledgments}

The EOLES and e-LIVES projects are funded by the European Commission under contract numbers 530466-TEMPUS-1-2012-1-FR-TEMPUS-JPCR and 585938-EPP-1-2017-1-FR-EPPKA2-CBHE-JP respectively. The European Commission support for the production of this publication does not constitute an endorsement of the contents which reflects the views only of the authors, and the Commission cannot be held responsible for any use which may be made of the information contained therein.

\section{References}

Albu, M., Holbert, K., Heydt, G., Grigorescu, S. \& Trusca, V. (2004). Embedding Remote Experimentation in Power Engineering Education, IEEE Transactions on Power Systems, 19(1), $139-143$

BigBlueButton (2019). Home - BigBlueButton. Retrieved March, 21, 2019 from http://bigbluebutton.org

Brinson, J. R. (2015) Learning outcome achievement in non-traditional (virtual and remote) versus traditional (hands-on) laboratories: A review of the empirical research, Computers \& Education, 87, 218-237.

Cardoso, A. \& Gil, P. (2013). Online Learning in Engineering Courses Using Wireless Sensor and Actuator Networks, International Journal of Engineering Pedagogy, 3(S1).

E-LIVES (2019). e-LIVES Project. Retrieved March, 21, 2019 from http://www.e-lives.eu

EOLES (2016), EOLES TEMPUS Project. Retrieved March 19, 2019 from http://www.eoles.eu

Garcia-Zubia, J., Angulo, I., Irurzun, J., Orduna, P., Ruiz, J., Hernandez, U., Castro, M. \& San-Cristobal, E. (2010), Easily Integrable Platform for the Deployment of a Remote Laboratory for Microcontrollers. International Journal of Online Engineering, 6(3).

Hercog, D., Gergic, B., Uran, S. \& Jezernik, K. (2007), A DSP-Based Remote Control Laboratory. IEEE Transactions on Industrial Electronics, 54(6), 3057-3068.

L3-EOLES (2019), Presentation - L3-EOLES. Retrieved March, 21, 2019 from http://13-eoles.unilim.fr/?lang=en

Matthews, D. (1999). The Origins of Distance Education and its use in the United States. T.H.E. Journal 27(2), 54-67.

Pells, R. (2019). The THE-Microsoft survey on AI. Retrieved March 29, 2019 from https://www.timeshighereducation.com/features/microsoft-survey-ai

Priem, F., De Craemer, R., Calu, J., Pedreschi, F., Zimmer, T., Saighi, S. \& Lilja, J. (2011), E-Learning in Science and Technology via a Common Learning Platform in a Lifelong Learning Project, European Journal of Open, Distance and E-Learning, (1).

Restivo, M., Mendes, J., Lopes, A., Silva, C. \& Chouzal, F. (2009), A Remote Laboratory in Engineering Measurement, IEEE Transactions on Industrial Electronics, 56(12), 4836-4843.

Said, F., Abdelhalim, B., Guillaume, N. \& Denis, B. (2012), Design of a Flexible Hardware Interface for Multiple Remote Electronic Practical Experiments of Virtual Laboratory, International Journal of Online Engineering, 8(S2).

Sousa, N., Alves, G. \& Gericota, M. (2010), An Integrated Reusable Remote Laboratory to Complement Electronics Teaching, IEEE Transactions on Learning Technologies, 3(3), 265-271.

UoL (2019). History of University of London. Retrieved March 12, 2019 from https://london.ac.uk/aboutus/history-university-london

Zhu, J. (2010). A hybrid online-education strategy for delivering engineering and technology courses. Proc. 2nd Intl. Conf. on Networking and Digital Society 2, 448-451. 